\title{
Preparation of Hierarchical BiOBr Microspheres for Visible Light-Induced Photocatalytic Detoxification and Disinfection
}

\author{
Ayla Ahmad, Xiangchao Meng, Nan Yun, and Zisheng Zhang \\ Department of Chemical and Biological Engineering, University of Ottawa, Ottawa, ON, Canada K1N 6N5 \\ Correspondence should be addressed to Zisheng Zhang; zzhang@uottawa.ca
}

Received 21 August 2016; Accepted 9 November 2016

Academic Editor: P. Davide Cozzoli

Copyright ( 2016 Ayla Ahmad et al. This is an open access article distributed under the Creative Commons Attribution License, which permits unrestricted use, distribution, and reproduction in any medium, provided the original work is properly cited.

\begin{abstract}
Photocatalytic degradation is a promising alternative to traditional wastewater treatment methods. Recently developed visible light-responsive photocatalyst, $\mathrm{BiOBr}$, has attracted extensive attentions. Hereby, a detailed investigation of application of $\mathrm{BiOBr}$ to bacterial inactivation and organic pollutants degradation is reported. Hydrothermal catalyst was prepared using templatefree method. While, for solvothermal synthesis, CTAB was used as a template. Results indicate a higher photocatalytic activity by the solvothermally prepared catalyst. Solvothermally prepared $\mathrm{BiOBr}$ exhibited high photocatalytic activities in both water detoxification and disinfection.
\end{abstract}

\section{Introduction}

A growing number of water sources are polluted not only with hazardous organic and inorganic chemicals but also with pathogenic microorganisms which has evolved as a growing problem all over the world [1-3]. An estimated 1.1 billion people lack access to clean drinking water, putting them at an increased risk of contracting waterborne illnesses $[4,5]$. In order to combat presence of disease causing microorganisms, chemical oxidation technologies such as chlorination and ozonation have been applied to drinking water treatment $[6,7]$. However, despite the use of these technologies with considerable efficiency, several issues related to these processes have become apparent. The chlorination of organic compounds in water may lead to the formation of harmful and undesirable by-products, such as trihalomethanes and chlorophenols, which are known to be mutagenic $[8,9]$. Chemical oxidation processes, particularly ozonation, require expensive chemicals and equipment for onsite disinfection and possibly result in secondary pollution $[9,10]$.

Ever since Matsunaga and coworkers reported the bactericidal effect of $\mathrm{TiO}_{2}$ photocatalyst under UV irradiation for the first time in 1985 [11], photocatalytic disinfection has been extensively carried out for disinfection and inactivation of microorganisms in water. Advanced oxidation processes (AOPs), including photocatalysis, offer good potential alternative disinfection of drinking water particularly in developing countries where solar irradiation may be employed for the disinfection process. Reactive radicals produced in photocatalytic processes can degrade a wide range of chemical compounds and inactivate harmful microorganisms in potable water [12]. However, $\mathrm{TiO}_{2}$ based photocatalytic processes are limited due to its poor quantum efficiency and wide band gap which allows it to only absorb in the UV light region. Since UV light forms only $5 \%$ of the entire solar energy, the utilization of solar radiation for such photocatalytic processes is not possible [13]. Several methods have been employed in order to make $\mathrm{TiO}_{2}$ compatible with solar light by shifting its optical response towards visible light region. Approaches that include doping $\mathrm{TiO}_{2}$ with transition metals or nonmetals and dye sensitization have been applied in studies with considerable improvement of visible light absorption of $\mathrm{TiO}_{2}$ [14]. Despite reported improvements in absorption, enhanced $\mathrm{TiO}_{2}$ photocatalysts present several limitations such as toxicity and self-photodegradation of organic dye, instability of metal-doped titania, and low absorption efficiency of nonmetal-doped titania in visible light region [15]. As a result, research is still ongoing to discover a photocatalyst with narrow band gap which can be activated by visible light and can effectively bring about degradation of pollutants. 
In recent times, bismuth oxyhalides, $\mathrm{BiOX}(\mathrm{X}=\mathrm{Cl}, \mathrm{Br}$, I), have been extensively applied in research due to their unique optical properties and favorable potential industrial applications [16-19]. Among the bismuth oxyhalides, $\mathrm{BiOBr}$ is of particular prominence due to its high activity and stability under visible light irradiation and demonstration of efficient degradation of a variety of pollutants under various conditions. The electrical, optical, and photocatalytic properties of $\mathrm{BiOBr}$ are due to its intrinsic crystalline layer and lamellar structure which make it distinctive as a photocatalyst [20]. And previous reports showed that the hierarchal structures could enhance the light utilization efficiency through light reflecting and scattering effects [2123]. Herein, we synthesized $\mathrm{BiOBr}$ using both hydrothermal and solvothermal routes and subsequently investigated the photocatalytic degradation of dye model, Rhodamine $B$, and colorless model, phenol, as well as disinfection of E. coli, under visible light irradiation.

\section{Experimental}

2.1. Materials. Cetyltrimethylammonium bromide (CTAB) (purity > 99\%) was obtained from Sigma Aldrich (Canada) and was used as obtained. Laboratory grade bismuth nitrate pentahydrate $\left(\mathrm{Bi}\left(\mathrm{NO}_{3}\right)_{3} \cdot 5 \mathrm{H}_{2} \mathrm{O}\right)$, ethylene glycol (EG), Rhodamine $\mathrm{B}(\mathrm{RhB})$, and ethanol were obtained from Fisher Scientific (Canada) and were used without any further alteration. Crystallized phenol (purity $>99 \%$ ) from Fisher Scientific was used for phenol studies. $\mathrm{HCl}$ and $\mathrm{NaOH}$ solutions were used for $\mathrm{pH}$ adjustment and were both obtained from Fisher Scientific and used without any further purification. Distilled deionized (DD) water, obtained by using a Milli-Q water purification system by Millipore (Canada), was used throughout the experiment in order to prevent interference from other ions. Wild-type Escherichia coli (K12, TG1 strain) was used as the model bacterium for the all bacterial inactivation studies. This strain was selected, since it is known to be nonpathogenic, as a common model used in laboratory experiments.

2.2. Preparation of $\mathrm{BiOBr}$. BiOBr samples were synthesized using a template-free hydrothermal synthesis process. Typically, $1.00 \mathrm{~g}$ of $\mathrm{Bi}\left(\mathrm{NO}_{3}\right)_{3} \cdot 5 \mathrm{H}_{2} \mathrm{O}$ was dissolved in $3 \mathrm{~mL}$ acetic acid (HAc) and was dissolved in $30 \mathrm{~mL} \mathrm{DD}$ water containing $0.24 \mathrm{~g} \mathrm{KBr}$ while stirring magnetically. Upon mixing of the two solutions, yellow precipitates of $\mathrm{BiOBr}$ were immediately observed. After stirring for $20 \mathrm{~min}$ at room temperature, the suspension was transferred into a Teflon-lined stainless steel autoclave and heated at $120^{\circ} \mathrm{C}$ for $6 \mathrm{~h}$. The resulting precipitate was filtered, washed thoroughly with DD water to remove any possible ionic species in the product, and then dried at $60^{\circ} \mathrm{C}$ to obtain $\mathrm{BiOBr}$ as a dried powder.

$\mathrm{BiOBr}$ was also prepared via a solvothermal synthesis method using $\mathrm{Bi}\left(\mathrm{NO}_{3}\right)_{3} \cdot 5 \mathrm{H}_{2} \mathrm{O}$ as the $\mathrm{Bi}$ source. A common surfactant $\mathrm{CTAB}$ was used in the synthesis route and it acted as a template as well as a bromide source for the final product. Initially, $0.75 \mathrm{~g}$ of CTAB was dissolved in $40 \mathrm{~mL}$ of EG solution. Upon complete dissolution of CTAB in $\mathrm{EG}, 1.00 \mathrm{~g}$ of $\mathrm{Bi}\left(\mathrm{NO}_{3}\right)_{3} \cdot 5 \mathrm{H}_{2} \mathrm{O}$ was added such that the ratio between $\mathrm{CTAB}$ and $\mathrm{Bi}\left(\mathrm{NO}_{3}\right)_{3} \cdot 5 \mathrm{H}_{2} \mathrm{O}$ was maintained as $1: 1$. The resulting solution was stirred magnetically for $20 \mathrm{~min}$ at room temperature, and the mixture was transferred to a Teflon-lined stainless steel autoclave and heated in an oven at a temperature of $180^{\circ} \mathrm{C}$ for 3 hours. After cooling down to room temperature, the resulting precipitate was filtrated, washed with DD water and ethanol several times, to remove ionic and organic species, and then dried at $60^{\circ} \mathrm{C}$ overnight.

2.3. Characterization. The crystal structures and purity of the prepared samples were characterized by X-ray powder diffraction (XRD) with a Rigaku Ultima IV $\mathrm{Cu}-\mathrm{K} \alpha(\lambda=$ $0.15418 \mathrm{~mm}$ ) radiation diffractometer and recorded with $2 \theta$ scope ranging within $10-80^{\circ}$. Scanning electron microscopy (SEM) was used to take images of the prepared $\mathrm{BiOBr}$ samples employing a Tescan Vega-II XMU field emission SEM with accelerating voltage of 5 or $20 \mathrm{kV}$. UV-vis diffusion reflectance spectra of the samples were analyzed with a UVvis spectrophotometer (Thermo Evolution 300) equipped with an accessory to analyze powder samples.

\subsection{Photocatalytic Degradation of Organics ( $R h B$ and Phenol).} In order to test the degradation of organics by $\mathrm{BiOBr}$, $250 \mathrm{~mL}$ of $10 \mathrm{ppm} \mathrm{RhB}$ solution (or $20 \mathrm{ppm}$ phenol) was added to the slurry based batch-reactor. In each batch, $1.0 \mathrm{~g} / \mathrm{L}$ of $\mathrm{BiOBr}$ was added to the solution and the slurry was magnetically stirred in dark for 40 minutes in order to ensure establishment of adsorption-desorption equilibrium. A 300 Watt ELH tungsten halide bulb (Ushio) was used to mimic sunlight and a cut-off filter was used to filter out any radiation below $410 \mathrm{~nm}$ ensuring that the photocatalysis was carried out strictly under visible light irradiation. A $2.5 \mathrm{~mL}$ sample was taken from the reactor at certain time intervals and photocatalyst was separated from the solution by centrifugation. The optical density of the filtrate was analyzed by UVvis spectrophotometer (at $554 \mathrm{~nm}$ for $\mathrm{RhB}$ and $270 \mathrm{~nm}$ for phenol, resp.), and the concentration of organic at each time interval was determined by using characterization curve of the organic.

2.5. Photocatalytic Disinfection Test. For the disinfection test, the number of viable bacterial cells was determined in terms of the colonies formed and diluted folds since these give insight into the culturability of bacteria. The starting bacterial culture was prepared by growing E. coli (K12) aerobically in Luria-Bertani nutrient solution (Difco LB Broth, Miller; containing $10 \mathrm{~g} / \mathrm{L}$ tryptone, $5 \mathrm{~g} / \mathrm{L}$ yeast extract, and $10 \mathrm{~g} / \mathrm{L}$ $\mathrm{NaCl}$ ) at $37^{\circ} \mathrm{C}$ with constant shaking at $250 \mathrm{rpm}$ until the stationary phase was reached. The initial concentration from the overnight culture was determined from a serial dilution using $0.9 \%$ sterilized saline and by plating $25 \mu \mathrm{L}$ of the bacterial solution on LB agar plates. The initial bacterial suspension was prepared by diluting the initial culture such that the bacterial concentration in starting solution would be $10^{6} \mathrm{CFU} / \mathrm{mL}$. It was prepared by taking diluted solution and centrifuging it at $14800 \mathrm{rpm}$ for 5 minutes. The bacterial pellet obtained from centrifugation was resuspended in $0.9 \%$ sterilized saline. This centrifugation and washing procedure was repeated three times to remove all growth media. $1 \mathrm{~mL}$ of 


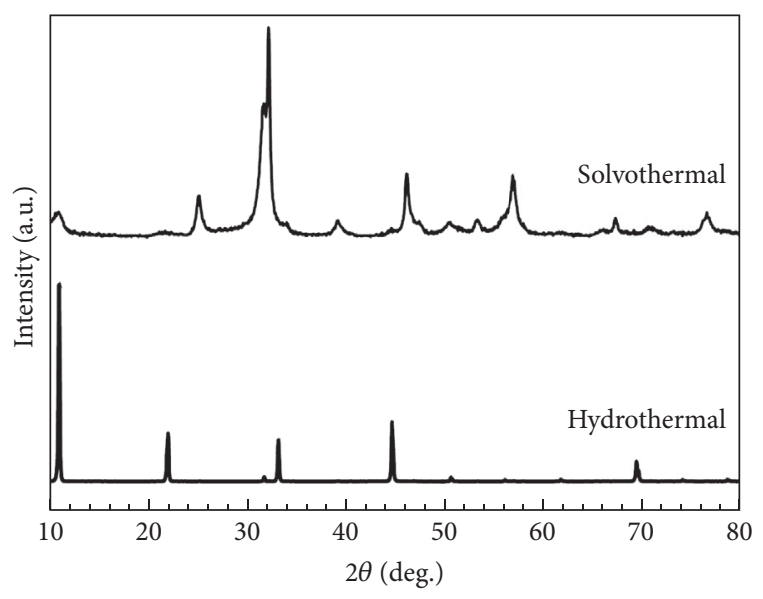

FIGURE 1: XRD patterns of $\mathrm{BiOBr}$ synthesized by hydrothermal and solvothermal method.

the bacterial sample was finally added to $49 \mathrm{~mL}$ of the saline in order to obtain $50 \mathrm{~mL}$ of initial starting solution with a bacterial concentration of $10^{6} \mathrm{CFU} / \mathrm{mL}$.

The temporal course of bacterial inactivation was studied by adding the abovementioned $50 \mathrm{~mL}$ starting solution to a $100 \mathrm{~mL}$ Pyrex beaker and adding $1 \mathrm{~g} / \mathrm{L} \mathrm{BiOBr}$ photocatalyst to it. The sample was then exposed to visible light irradiation provided by a 300 Watt ELH tungsten halide bulb (Ushio, United States) equipped with a UV filter (Kenko Zeta, $\lambda>$ $410 \mathrm{~nm}$ ) in order for the photocatalysis induced disinfection to occur. The mixture was magnetically stirred at $160 \mathrm{rpm}$ at all times to keep the photocatalyst-bacteria slurry in suspension. During the disinfection process, the temperature was rigorously maintained at $20^{\circ} \mathrm{C} \pm 2$ using a water bath in order to dissuade changes in bacterial population due to temperature changes. Samples were collected at planned periods and were serially diluted in saline and then spread onto LB agar plates using aliquot volumes ranging within $25-100 \mu \mathrm{L}$. Aliquots from each sample were spread on three separate LB agar plates for each dilution and incubated at $37^{\circ} \mathrm{C}$ for 18 hours. The bacteria were quantified using standard plate count method (for viable and cultivable bacteria), whereby counts in the range of 30-300 colony forming units (CFU) per plate were considered statistically significant and were used to calculate the viable cell concentration. All bacterial inactivation trials were performed in triplicate due to high degree of uncertainty in biological experiments. In order to prevent contamination from outside sources, sterilization and containment measures were taken and all containers and tools used in the study were sterilized for 20 minutes at $121^{\circ} \mathrm{C}$ prior to use.

\section{Results and Discussions}

3.1. XRD Analysis. The purity and crystallinity of the obtained $\mathrm{BiOBr}$ samples were examined using powder XRD measurements. Figure 1 shows the XRD patterns of $\mathrm{BiOBr}$ samples synthesized by hydrothermal (h-BiOBr) and solvothermal (s-BiOBr) methods. All the detectable peaks in the pattern of $\mathrm{h}-\mathrm{BiOBr}$ were assigned to tetragonal phase of $\mathrm{BiOBr}$ (JCPDS card number 09-0393; $a=b=3.92 \AA$, $c=8.10 \AA$, and $\alpha=\beta=\gamma=90^{\circ}$ ) [24] and no impurity peaks were detected, showing high purity of the crystal. The peaks are narrow and intense which implies good crystallinity of $\mathrm{BiOBr}$ samples. The intensities of the diffraction peaks with $\left(\begin{array}{lll}0 & 0 & 1\end{array}\right)$ series are much stronger than others which shows that the samples are anisotropic and grew along the $\left(\begin{array}{lll}0 & 0 & 3\end{array}\right)$ plane which is in accordance with the crystal structure of $\mathrm{BiOBr}$ (Shang et al., 2009). For XRD patterns of s-BiOBr samples shown in Figure 1, all the peaks were also indexed to the tetragonal phase of $\mathrm{BiOBr}$ (JCPDS card number 73-2061) [25]. s- $\mathrm{BiOBr}$ samples display a high amount of purity as established by lack of impurity peaks. The narrow broadening of peaks implies well crystallized material. The wide peaks also suggest that the crystalline size of samples is small. The most intense peak occurs at the (110) position which implies growth in that direction.

3.2. SEM Analysis. The morphology of $\mathrm{BiOBr}$ catalyst was characterized by scanning electron microscopy (SEM). It can be noted that the hydrothermally produced $\mathrm{BiOBr}$ crystals form nanoplates, while those produced solvothermally appear as microspheres (Figures 2(a), 2(b), and 2(c)). The hydrothermal flakes/plates have an average thickness of $11.3 \mu \mathrm{m}$ with a wider size distribution. The surface of nanoplates is smooth. As reported [26], $\mathrm{BiOBr}$ may be hydrothermally prepared with flakes morphology in acidic aqueous solution and varied morphologies in alkaline condition. The microspheres (Figure 2(d)) are somewhat uniform in size with an average diameter of $4.7 \mu \mathrm{m}$. CTAB serves not only as the template but also as the $\mathrm{Br}$ source. As a template, $\mathrm{CTAB}$ are able to self-aggregate into various structures, such as cubic, hexagonal, and lamellar structure [27]. CTAB offer robust chemical and mechanical stability and prevent the aggregation of $\mathrm{BiOBr}$ nanosheets. Also, EG interacts with metal ions to produce alkoxides which causes the separation of nucleation and growth [20]. This could possibly assist in the formation of 3D microspheres; however, the reason for this morphology is not entirely known. The exterior surface of microspheres is not smooth but consists of thread-like fibers. This increases the ability of catalyst to separate and conduct photogenerated hole-electron pair efficiently [27]. The 3D spherical structure also provides a higher surface area to the catalyst, suggesting that the performance of these structures may be better than that of the plates.

3.3. Diffuse Reflectance Spectra (DRS). The optical properties of $\mathrm{BiOBr}$ were investigated using UV-vis spectroscopy. The diffuse reflectance spectra of $\mathrm{BiOBr}$ hydrothermal and solvothermal samples are shown in Figure 3. All samples indicate an increase in photoabsorption below 475 and suggests that these photocatalysts would be active under visible light. The band gap transition for both samples is comparable. The band gaps of samples were obtained via Tauc plots and it was found to be $2.82 \mathrm{eV}$ for hydrothermally synthesized photocatalyst, while that for solvothermal sample was $2.90 \mathrm{eV}$. 


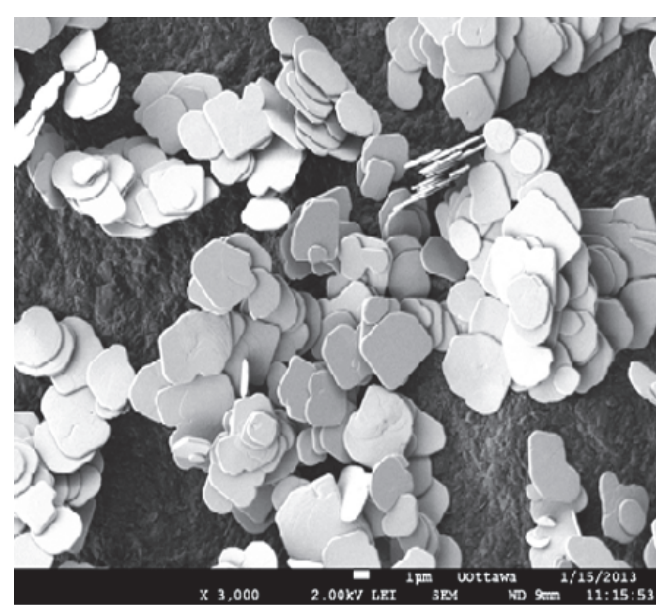

(a)

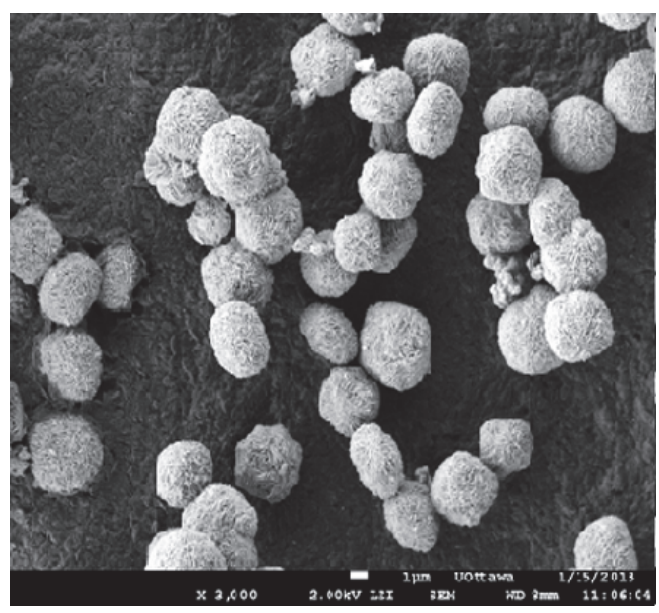

(c)

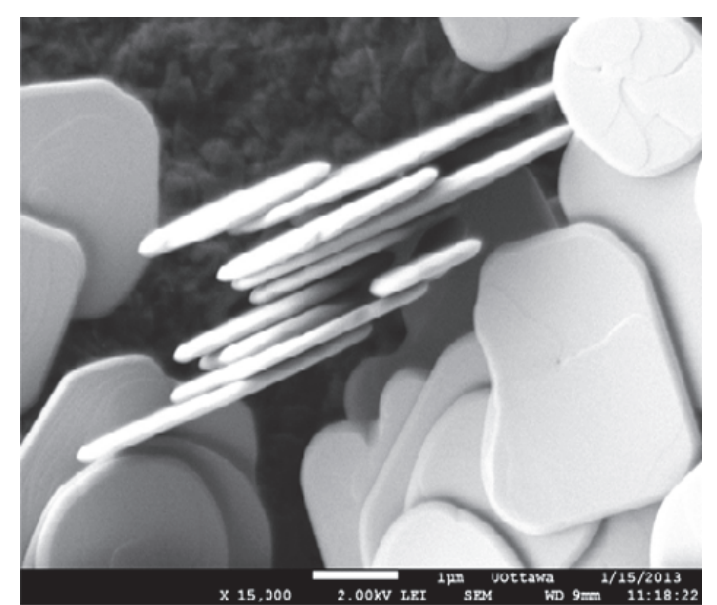

(b)

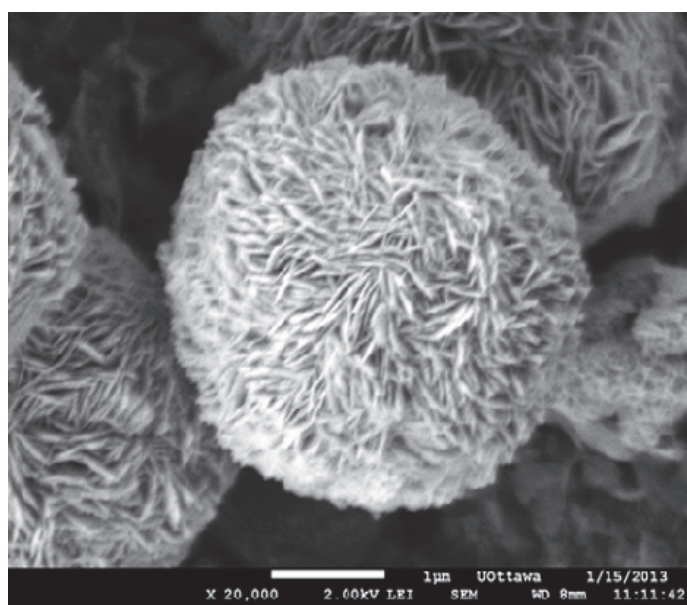

(d)

FIGURE 2: SEM images of BiOBr prepared by hydrothermal method at (a) low and (b) high magnification and solvothermal method at (c) low and (d) high magnification.

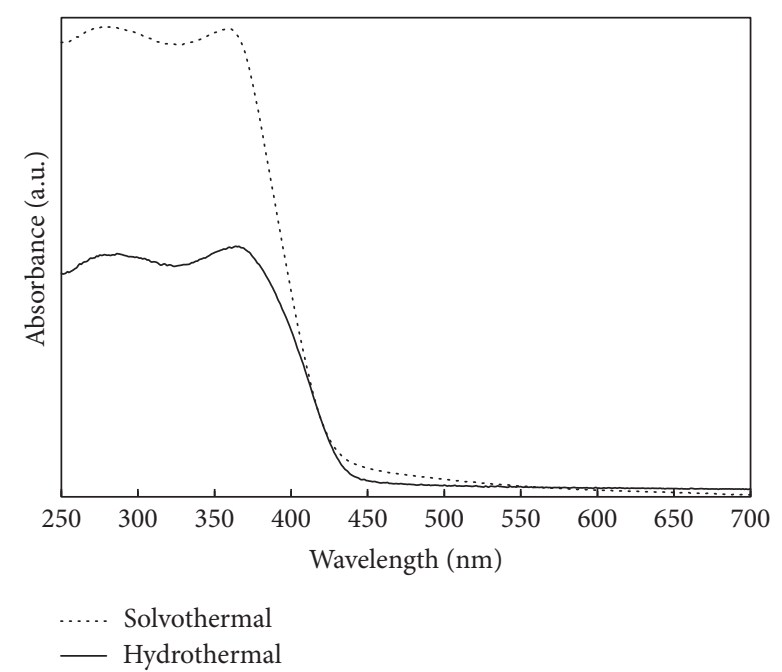

FIGURE 3: DRS of BiOBr prepared by hydrothermal and solvothermal methods.

\subsection{Photocatalytic Degradation of Rhodamine B}

3.4.1. Comparison of Preparation Methods. Photocatalytic activities of $\mathrm{h}-\mathrm{BiOBr}$ and $\mathrm{s}-\mathrm{BiOBr}$ were investigated by degrading $\mathrm{RhB}$ under visible light irradiation, results of which were shown in Figure 4 . In the photolysis test, about $12 \%$ of $\mathrm{RhB}$ were removed without adding catalyst under visible light irradiation, which can be attributed to the photosensitization effect. The removal efficiencies of RhB in first $10 \mathrm{~min}$ were $35.5 \%$ and $55 \%$ for systems with $\mathrm{h}-\mathrm{BiOBr}$ and $\mathrm{s}-\mathrm{BiOBr}$, respectively. And $100 \%$ removal efficiency was obtained at 50 and $70 \mathrm{~min}$, respectively, for systems with s$\mathrm{BiOBr}$ and h-BiOBr. Pseudo-first-order model was employed by plotting $\ln \left(c_{0} / c\right)$ as a function of time $(t)$ [17], to evaluate the photocatalytic kinetics of systems with $\mathrm{BiOBr}$. In the inset of Figure 4, the reaction constants for systems with $\mathrm{h}-\mathrm{BiOBr}$ and $\mathrm{s}-\mathrm{BiOBr}$ were 0.058 and $0.078 \mathrm{~min}^{-1}$, respectively. It indicated that samples prepared by solvothermal synthesis method displayed better photocatalytic activity than those prepared by hydrothermal method. The superior 


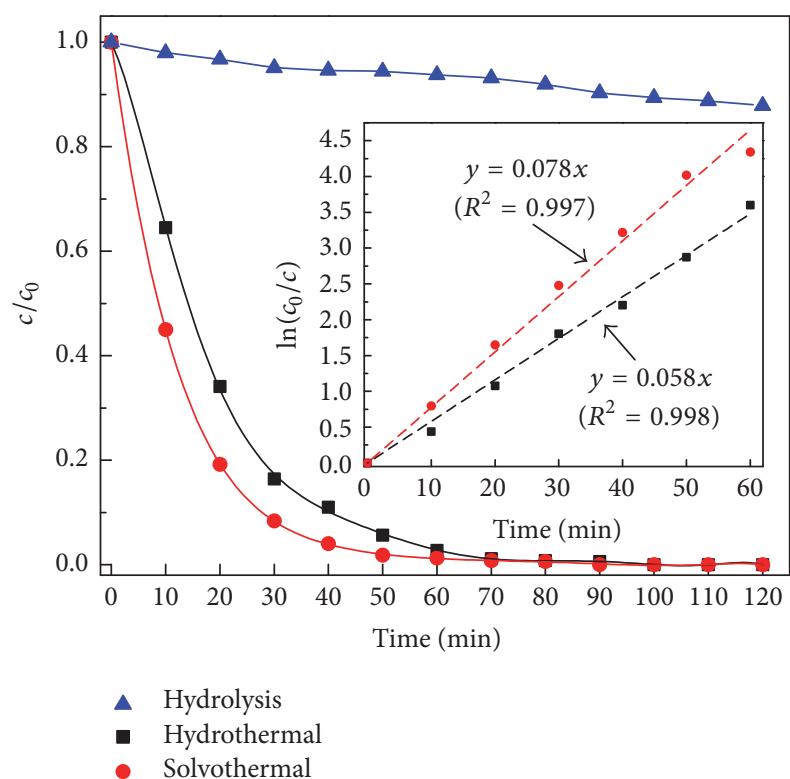

Figure 4: Concentration profiles of RhB during photolysis process and photocatalytic degradations with h-BiOBr and s- $\mathrm{BiOBr}$, respectively, under visible light irradiation. (Inset: kinetics analysis of these two systems.)

performance by solvothermal samples is possibly due to their microspherical morphology which consists of nanoscale building blocks. The 3D spherical structure with rough fibers on the surface increases the surface to volume ratio of the catalyst. These hierarchal structures also have higher adsorption capacity which allows more efficient transport for the reactant molecules to active sites. Moreover, formation of these template aided structures prevents aggregation of nanosheets, in contrast with the hydrothermal structures, which facilitates degradation of pollution molecules due to better separation of electrons and holes. Therefore, solvothermal synthesis method shows more efficient results than that obtained by hydrothermal synthesis.

3.4.2. Effects of Catalysts Dosage Amounts. The catalyst loading for the photocatalytic degradation process is an important parameter as it determines the amount of catalyst expended per cycle and therefore an optimum loading must be determined. The effect of initial catalyst loading for the optimized solvothermal photocatalyst is demonstrated in Figure 5, whereby the catalyst dosage was varied from $0.25 \mathrm{~g} / \mathrm{L}$ to $1.50 \mathrm{~g} / \mathrm{L}$ for the same pollutant concentration. It can be noted that as catalyst dosage is increased from $0.25 \mathrm{~g} / \mathrm{L}$ and the activity also increases up to a catalyst dosage of $1.00 \mathrm{~g} / \mathrm{L}$. The rate constant for degradation of $\mathrm{RhB}$ at this value is $0.104 \mathrm{~min}^{-1}$ (Figure 6). Beyond a concentration of $1.00 \mathrm{~g} / \mathrm{L}$, a decrease is noted in the activity and, for a dosage of $1.50 \mathrm{~g} / \mathrm{L}$, the rate constant is decreased to $0.066 \mathrm{~min}^{-1}$ (Figure 6) which is roughly $2 / 3$ of that for $1.00 \mathrm{~g} / \mathrm{L}$. This result is expected since as the amount of catalyst is increased, the number of available active sites is increased, which increases the amount of hydroxyl radicals produced, thus enhancing the photocatalytic activity $[28,29]$. However,

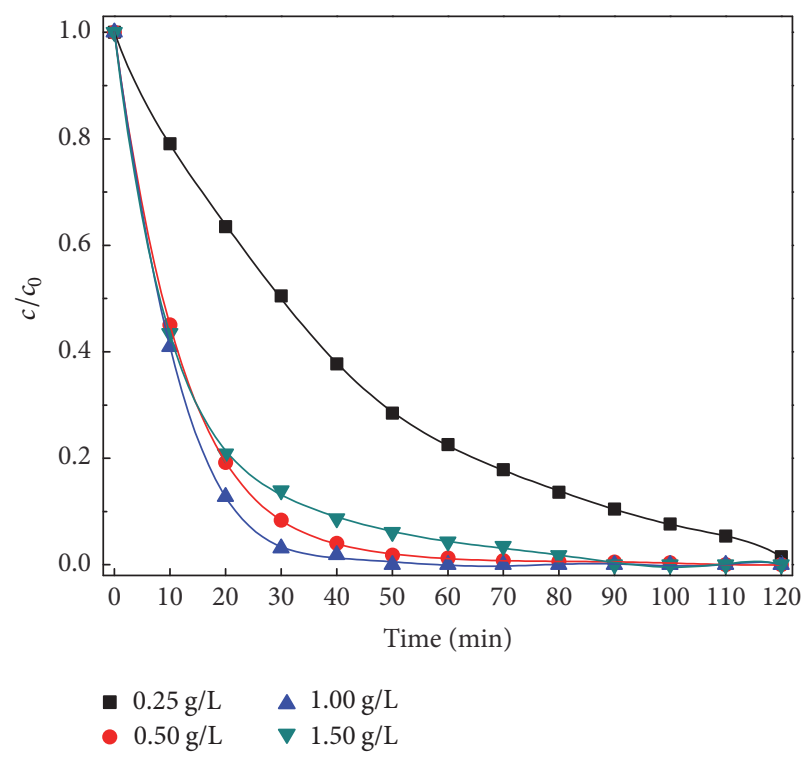

FIGURE 5: Effect of catalysts loading on photocatalytic activity of s$\mathrm{BiOBr}$.

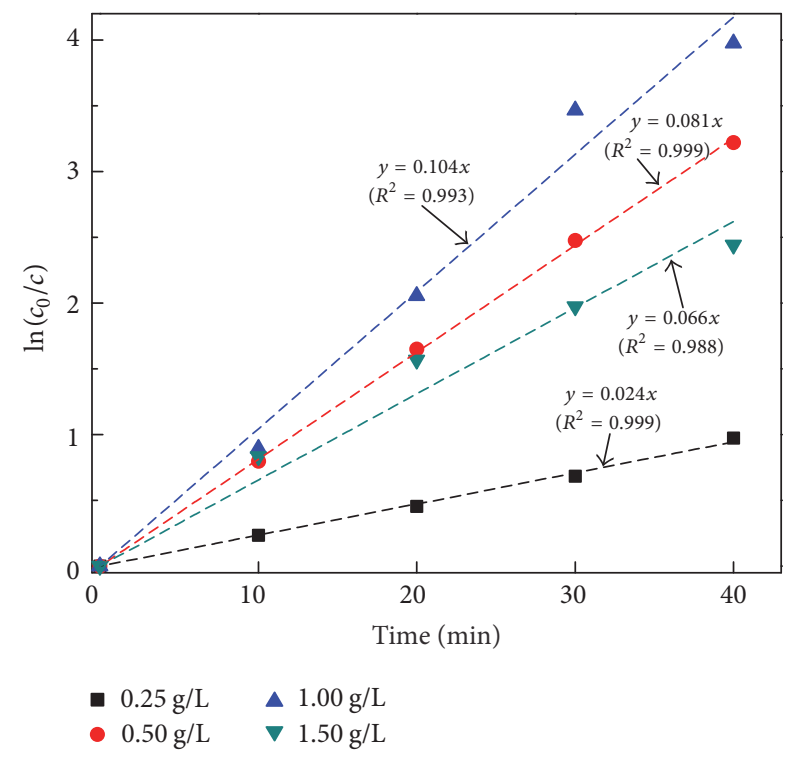

FIgURE 6: Photocatalytic degradation rate constants for systems with various catalyst loadings.

increasing the catalyst loading excessively negatively affects the photocatalytic activity due to a higher extent of light scattering which decreases the light penetration [30-32]. As a result, the photocatalytic activity is reduced and a dosage of $1.00 \mathrm{~g} / \mathrm{L}$ is deemed as the optimized dosage.

3.4.3. Effects of $p H$. The $\mathrm{pH}$ value of the solution is an important factor influencing the degradation of some pollutants in the photocatalytic process and can also be a critical operational variable $[10,33]$. Altering the initial $\mathrm{pH}$ may vary electrostatic interaction between the reactant and $\mathrm{BiOBr}$ surface and also shift the potential of redox reaction affecting 


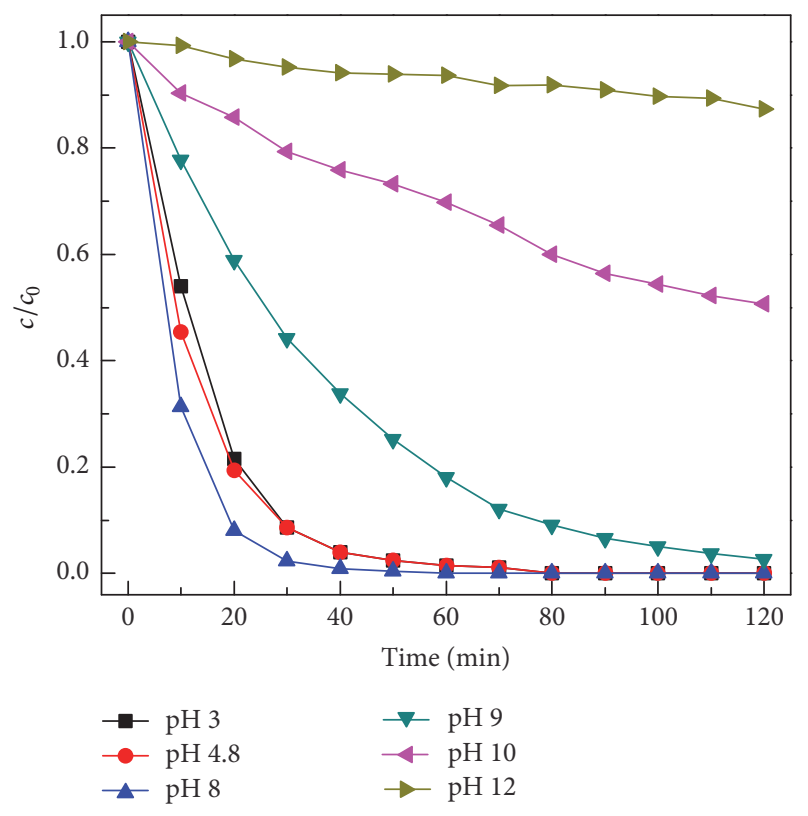

Figure 7: Effect of $\mathrm{pH}$ on degradation of $\mathrm{RhB}$ by s-BiOBr photocatalyst under visible light.

the adsorption and reactivity of organic solutes [34]. This parameter is also important since the $\mathrm{pH}$ of water may differ based on the source it is received from and it must be determined whether the particular $\mathrm{pH}$ is operational or an adjustment is required prior to treatment. The effect of $\mathrm{pH}$ on the degradation performance of the solvothermally synthesized $\mathrm{BiOBr}$ is supposed therefore to be evaluated.

Influence of $\mathrm{pH}$ on the degradation of $\mathrm{RhB}$ by $\mathrm{BiOBr}$ was investigated by adjusting the $\mathrm{pH}$ to the desired value by using dilute $(0.5 \mathrm{M}$ or $1.0 \mathrm{M}) \mathrm{HCl}$ acidic or $\mathrm{NaOH}$ basic solutions. It should be noted that the $\mathrm{pH}$ value must be adjusted prior to the degradation reaction. The initial $\mathrm{pH}$ of $10 \mathrm{ppm} \mathrm{RhB}$ without any adjustment was found to be 4.8 in the deionized water solution. The effect of $\mathrm{pH}$ on degradation of $\mathrm{RhB}$ is presented in Figure 7 as follows. It can be noted from the figure that, at very low and high $\mathrm{pH}$ values, the degradation of $\mathrm{RhB}$ deteriorates significantly. When the $\mathrm{pH}$ is decreased below the initial $\mathrm{pH}$ of $\mathrm{RhB}(\mathrm{pH} 4.8)$, the rate of degradation is lower. However, as the $\mathrm{pH}$ is increased, the degradation rate increases, reaching a maximum at around $\mathrm{pH} 8$. Beyond this $\mathrm{pH}$, however, the activity decreases drastically and, at a $\mathrm{pH}$ of 12 , barely any degradation of RhB is observed.

The results obtained in this study demonstrate that the initial $\mathrm{pH}$ value of $\mathrm{RhB}$ aqueous solution has significant effect on the adsorption and photocatalytic degradation by photocatalyst $\mathrm{BiOBr}$ under visible light. The results can be explained by relating the effects of $\mathrm{pH}$ on surface charge of catalyst and pollutants, adsorption of contaminants on surface of the photocatalyst, and hydroxyl concentration, which ultimately affect the degradation efficiency [35]. The $\mathrm{pKa}$ value for the aromatic carboxyl group $(-\mathrm{COOH})$ present on $\mathrm{RhB}$ molecule is 4.0 [36]. When the solution $\mathrm{pH}$ is lower than $4.0, \mathrm{RhB}$ ion assumes a positive charge and if the $\mathrm{pH}$ is increased over 4.0, the ion takes on a negative charge.
Since the isoelectric point of $\mathrm{BiOBr}$ lies in the acidic range [35], both the catalyst and pollutant are positively charged at the lower $\mathrm{pH}$. As a result, the adsorption of $\mathrm{RhB}$ on the $\mathrm{BiOBr}$ surface is lower and this leads to lower degradation at lower $\mathrm{pH}$. An increase in degradation with increasing $\mathrm{pH}$ can be explained by the fact that, in alkaline media, a higher level of hydroxide ions $\left(\mathrm{OH}^{-}\right)$induced the generation of hydroxyl free radicals $\left(\mathrm{HO}^{\circ}\right)$. The formation of hydroxyl free radicals occurs from photooxidation of $\mathrm{OH}^{-}$by holes forming on the surface of the $\mathrm{BiOBr}$ photocatalyst [37]. Since hydroxyl free radicals are the primary oxidizing species in degradation of $\mathrm{RhB}$, the rate of degradation is increased as the $\mathrm{pH}$ of the solution is increased. However, as the $\mathrm{pH}$ is increased beyond the ideal $\mathrm{pH}$, the effect of negative charging of $\mathrm{BiOBr}$ dominates consequently inhibiting the degradation of $\mathrm{RhB}$. This is because the pollutant and $\mathrm{BiOBr}$ molecules at higher $\mathrm{pH}$ repel, which lowers the adsorption of $\mathrm{RhB}$ on the surface of photocatalyst, which is known to lead to poor photochemical degradation [38].

Therefore, an optimum $\mathrm{pH}$ exists for high photocatalytic activity of $\mathrm{BiOBr}$ which in this case is found to be around 8 . This is in agreement with the value obtained by Zhao's group for $\mathrm{BiOBr}$ synthesized via the hydrolysis method, suggesting effect of $\mathrm{pH}$ is independent of synthesis route. It was also established that $\mathrm{pH}$ values that are too high or too low are not favorable for $\mathrm{BiOBr}$ to decompose the $\mathrm{RhB}$ molecule which is also in agreement with literature and theory as stated [38].

3.4.4. Reusability. Recyclability tests were performed in similar manner to the photocatalytic activity tests, except for this case as the catalyst was recovered at the end of the run. The catalyst was filtered, washed, and then dried to regenerate it in powder form. Subsequent runs were then carried out with this catalyst sample. Here, only the solvothermally synthesized catalyst results are shown (Figure 8), but similar results were obtained for both solvothermal and hydrothermal samples. It indicated that the catalyst remains intact with negligible change in photocatalytic activity. This demonstrates that the $\mathrm{BiOBr}$ catalyst is stable and may be reused over many runs, which is an important prerequisite for any photocatalyst.

3.5. Photocatalytic Degradation of Phenol. In order to test applicability of $\mathrm{BiOBr}$ based photocatalysis to phenol and related compounds, phenol degradation was studied under visible irradiation. This also helps ascertain that degradation of pollutant by $\mathrm{BiOBr}$ is due to direct or indirect photocatalysis [39]. Since phenol is a colorless organic pollutant, its degradation was also studied to further confirm the occurrence of a surface photocatalytic process, which is not always endorsed by dyes, since they can undergo photosensitization under visible light irradiation [40].

The degradation of phenol is represented by in Figure 9 which shows normalized concentration $c / c_{0}$ as a function of time. No more than 3\% of phenol were decomposed under the photolysis effect, which is negligible. It can be noted that, under the given conditions, phenol could be degraded to some extent by $\mathrm{BiOBr}$ under visible light with final percent degradation after 4 hours of irradiation being 

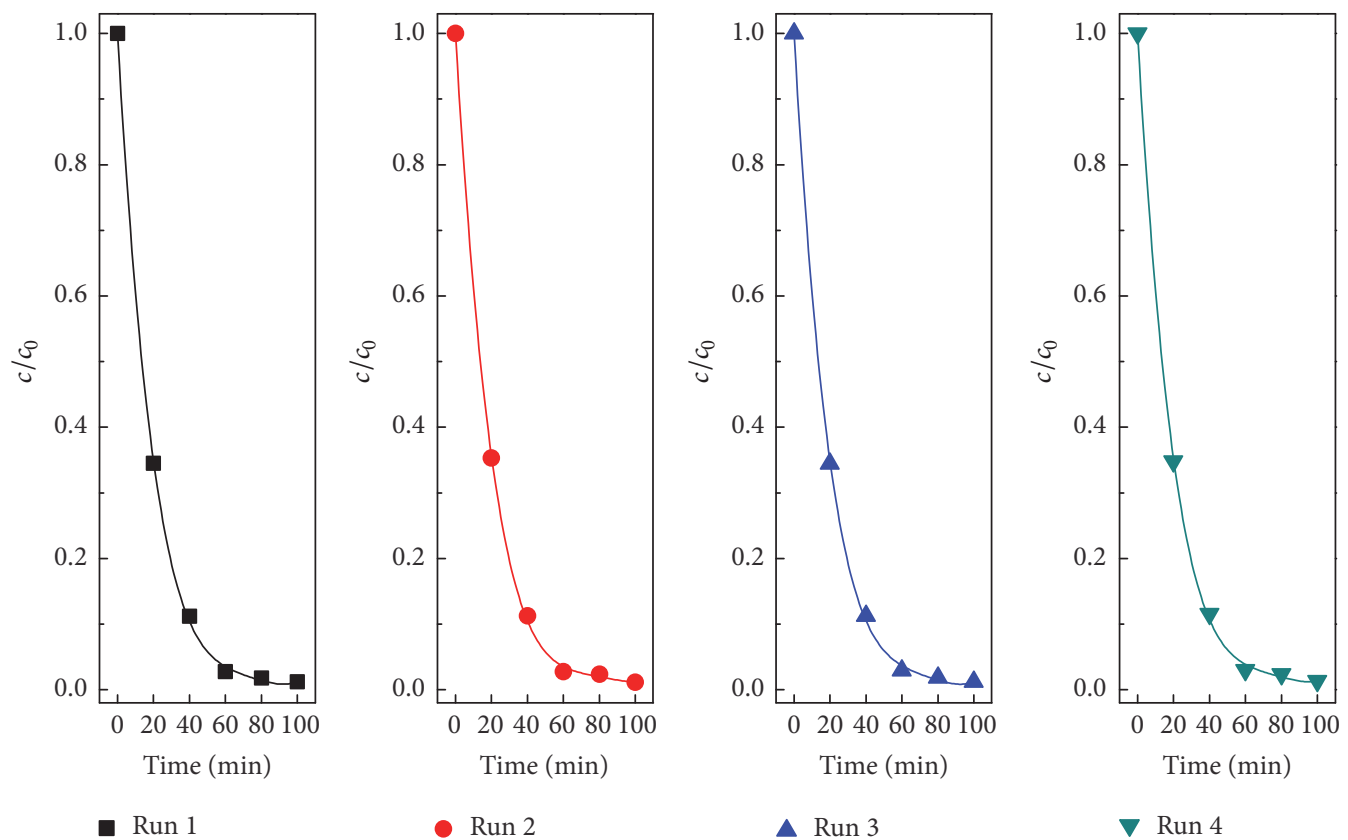

Figure 8: Recyclability tests for s-BiOBr catalysts.

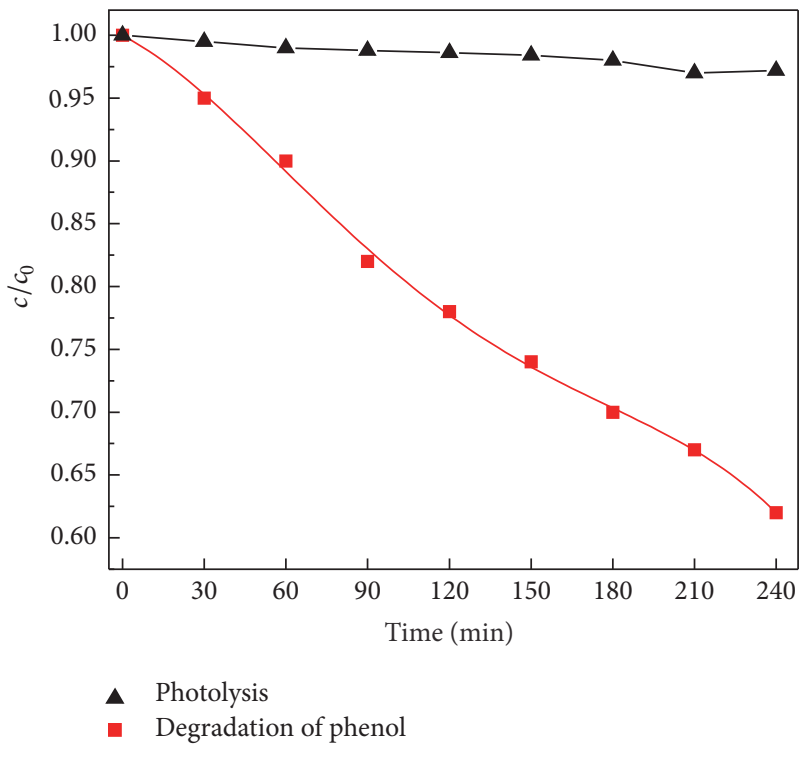

FIGURE 9: Photocatalytic degradation of phenol with s-BiOBr and photolysis of phenol under visible light irradiation.

$38 \%$. It can instantaneously be established that the activity of $\mathrm{BiOBr}$ in phenol solution is much lower than that in $\mathrm{RhB}$ solution. This is due to structural differences of phenol due to benzene rings making it more complex to degrade [41]. The low visible light activity of $\mathrm{BiOBr}$ in phenol degradation can be explained by the band structure of BiOBr. Wang's group calculated the band structure of $\mathrm{BiOBr}$ using planewave density function theory (DFT) in order to investigate intrinsic reasons for lower visible light performance of $\mathrm{BiOBr}$ [42]. It was found that since the conduction band of $\mathrm{BiOBr}$ was additionally positive, molecular oxygen cannot trap photogenerated electrons to produce reactive oxygen radicals $\left({ }^{\circ} \mathrm{O}_{2}{ }^{-}\right)[43,44]$. The generation of ${ }^{\circ} \mathrm{O}_{2}{ }^{-}$is an important process during photocatalysis since they inhibit the recombination of photo-induced charge carriers. Oxygen radicals would be especially beneficial in degradation of phenol and related compounds by favoring the breaking of benzene ring of phenol derivatives [45]. Therefore, the lower performance of $\mathrm{BiOBr}$ in phenol degradation under visible light can be attributed to undesirable positions of conduction bands which hinders its performance for phenol under visible light despite its merits of suitable band gap for visible light photocatalysis, layered structure, and indirect semiconductor [42].

3.6. Photocatalytic Disinfection Tests. Based on the vast photocatalytic properties of $\mathrm{BiOBr}$, it can be hypothesized that, in addition to degradation of chemical pollutants, $\mathrm{BiOBr}$ photocatalyst can be applied to the deactivation of pathogens. As discussed earlier, E. coli was selected as the model microorganism to evaluate the bactericidal activity of $\mathrm{BiOBr}$. The bacterial disinfection was performed under visible light since it is safe and cost effective relative to UV irradiation which is hazardous and expensive [46].

The results obtained from photocatalytic disinfection of E. coli using $\mathrm{BiOBr}$ as photocatalyst are demonstrated in Figure 10. The fractions of surviving bacteria were calculated as ratio $N_{t} / N_{0}$, where $N_{t}$ represents the bacterial concentration at the particular inactivation time and $N_{0}$ is the initial concentration $(t=0)$. It can be noted from the results that $95 \%$ of bacteria were inactivated within the first 60 minutes in the presence of $\mathrm{BiOBr}$ under visible light irradiation. On the other hand, the dark control representing inactivation of bacteria by $\mathrm{BiOBr}$ in the absence of any irradiation and 


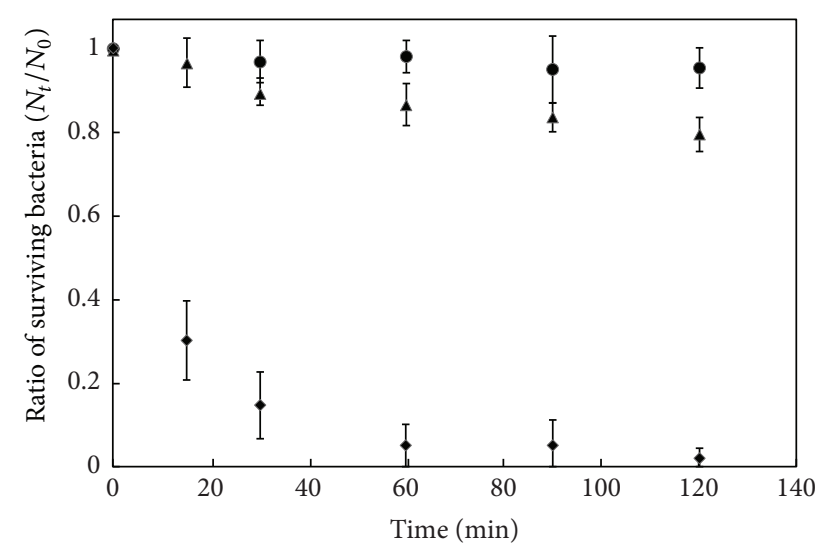

- Bacterial photolysis

- BiOBr dark adsorption

- BiOBr photocatalysis

Figure 10: Visible light inactivation of E. coli using s-BiOBr photocatalyst.

hence without any photocatalysis demonstrates very little inactivation. The ratio of bacteria inactivated is less than $20 \%$ even after 2 hours which is contrasted to over $98 \%$ of bacteria inactivated by $\mathrm{BiOBr}$ photocatalysis. The small ratio of inactivation in dark by $\mathrm{BiOBr}$ can be attributed to adsorption by the surface of the photocatalyst. The bacterial photolysis was performed by not adding any photocatalyst to the starting solution before exposing it to visible light irradiation. This run is representative of bacterial cell death in the absence of any adsorptive, antibacterial, or photocatalytic phenomena. It can be deduced from the results that inactivation of bacteria by the visible light source was found to be negligible.

On the basis of obtained results, it can be deduced that the death of bacterial cells in the presence of $\mathrm{BiOBr}$ was due to photocatalytic process when $\mathrm{BiOBr}$ was exposed to visible light irradiation. The oxygen species, such as hydroxyl radicals, formed during $\mathrm{BiOBr}$ photocatalysis are understood to interact with the E. coli bacteria to bring about cell destruction $[47,48]$. The main features of live E. coli are well defined cell membranes and presence of proteins, enzymes, and DNA [49]. Cell membranes in Gramnegative bacteria are characterized by an outer membrane containing lipopolysaccharides and an inner peptide layer [49]. The outer membrane plays the role of protecting the cell by providing a selective barrier preventing toxic molecules from entering the cell $[50,51]$. The oxygen species produced in $\mathrm{BiOBr}$ photocatalytic systems causes oxidation of functional groups in the cell membrane which disrupts membrane permeability leading to leakage of intracellular substances, destruction of microbial structure, and eventually the inactivation of E. coli $[49,52,53]$.

Reactive oxygen species are produced in most visible light-induced photocatalytic processes; however, the activity demonstrated by $\mathrm{BiOBr}$ is relatively higher. The high photocatalytic bactericidal activity of solvothermally produced $\mathrm{BiOBr}$ may be due to the strong adsorption capability induced by its microspherical structure, which allows it to adhere to the cell membrane better. It has been demonstrated in earlier reports [54] that microspheres exhibit much higher light absorption intensity than other sheet structures of $\mathrm{BiOBr}$. Therefore, the hierarchical microspherical structures caused light to multireflect between the $\mathrm{BiOBr}$ layers, allowing more light to be absorbed by $\mathrm{BiOBr}$ photocatalyst to generate electron-hole pairs for the photocatalyzed oxidation of $E$. coli [54]. BiOBr microspheres also offer a lower recombination rate for photogenerated electron-hole pairs and higher quantum efficiency which are all factors that contribute to its high performance in photocatalyst-induced disinfection [55].

\section{Conclusions}

$\mathrm{BiOBr}$ were successfully prepared using template-free hydrothermal as well as CTAB mediated solvothermal methods. In the photocatalytic activity tests, $\mathrm{s}-\mathrm{BiOBr}$ exhibited higher degradation efficiency with regard to RhB degradation, compared to h-BiOBr. And s-BiOBr were also able to photocatalytically degrade colorless organic pollutant, phenol, and inactive microorganism, E. coli, in wastewater. Possible affecting factors include catalyst loading and solution $\mathrm{pH}$ were explored in the presence of s-BiOBr samples under visible light irradiation. The high photocatalytic activity in decomposition of organic pollutants and inactivation of bacteria in wastewater suggest s-BiOBr may be a potential candidate in visible light-driven photocatalysis.

\section{Competing Interests}

The authors declare that they have no competing interests.

\section{Acknowledgments}

This work was financially supported by National Science and Engineering Research Council of Canada (NSERC) and the University of Ottawa. Ayla Ahmad was the recipient of a NSERC Canada Graduate Scholarship and Xiangchao Meng was the recipient of a China Scholarship Council Doctoral Scholarship for the duration of this work.

\section{References}

[1] E. Friehs, Y. AlSalka, R. Jonczyk et al., "Toxicity, phototoxicity and biocidal activity of nanoparticles employed in photocatalysis," Journal of Photochemistry and Photobiology C: Photochemistry Reviews, vol. 29, pp. 1-28, 2016.

[2] C. R. Holkar, A. J. Jadhav, D. V. Pinjari, N. M. Mahamuni, and A. B. Pandit, "A critical review on textile wastewater treatments: possible approaches," Journal of Environmental Management, vol. 182, pp. 351-366, 2016.

[3] X. Meng, Z. Zhang, and X. Li, "Synergetic photoelectrocatalytic reactors for environmental remediation: a review," Journal of Photochemistry and Photobiology C: Photochemistry Reviews, vol. 24, pp. 83-101, 2015.

[4] S. Ede, L. Hafner, P. Dunlop, J. Byrne, and G. Will, "Photocatalytic disinfection of bacterial pollutants using suspended and immobilized $\mathrm{TiO}_{2}$ powders," Photochemistry and Photobiology, vol. 88, no. 3, pp. 728-735, 2012. 
[5] L. Zhu, C. He, Y. Huang et al., "Enhanced photocatalytic disinfection of E. coli 8099 using Ag/BiOI composite under visible light irradiation," Separation and Purification Technology, vol. 91, pp. 59-66, 2012.

[6] J. Gibbons and S. Laha, "Water purification systems: a comparative analysis based on the occurrence of disinfection byproducts," Environmental Pollution, vol. 106, no. 3, pp. 425-428, 1999.

[7] E. H. Goslan, S. W. Krasner, M. Bower et al., "A comparison of disinfection by-products found in chlorinated and chloraminated drinking waters in Scotland," Water Research, vol. 43, no. 18, pp. 4698-4706, 2009.

[8] R. L. Jolley and J. H. Carpenter, "Review of the chemistry and environmental fate of reactive oxidant species in chlorinated water," in Proceedings of the 4th Conference on Water Chlorination: Environmental Impact and Health Effects, pp. 3-47, Lewis Publishers, 1990.

[9] P. S. M. Dunlop, J. A. Byrne, N. Manga, and B. R. Eggins, “The photocatalytic removal of bacterial pollutants from drinking water," Journal of Photochemistry and Photobiology A: Chemistry, vol. 148, no. 1-3, pp. 355-363, 2002.

[10] O. K. Dalrymple, E. Stefanakos, M. A. Trotz, and D. Y. Goswami, "A review of the mechanisms and modeling of photocatalytic disinfection," Applied Catalysis B: Environmental, vol. 98, no. 12, pp. 27-38, 2010.

[11] T. Matsunaga, R. Tomoda, T. Nakajima, and H. Wake, "Photoelectrochemical sterilization of microbial cells by semiconductor powders," FEMS Microbiology Letters, vol. 29, no. 1-2, pp. 211214, 1985.

[12] S. Malato, M. I. Maldonado, P. Fernández-Ibáñez, I. Oller, I. Polo, and R. Sánchez-Moreno, "Decontamination and disinfection of water by solar photocatalysis: the pilot plants of the Plataforma Solar de Almeria," Materials Science in Semiconductor Processing, vol. 42, pp. 15-23, 2016.

[13] L. Zhang, T. Kanki, N. Sano, and A. Toyoda, "Development of $\mathrm{TiO}_{2}$ photocatalyst reaction for water purification," Separation and Purification Technology, vol. 31, no. 1, pp. 105-110, 2003.

[14] N. S. Leyland, J. Podporska-Carroll, J. Browne, S. J. Hinder, B. Quilty, and S. C. Pillai, "Highly Efficient F, Cu doped $\mathrm{TiO}_{2}$ antibacterial visible light active photocatalytic coatings to combat hospital-acquired infections," Scientific Reports, vol. 6, Article ID 24770, 2016.

[15] X. Chen and S. S. Mao, "Titanium dioxide nanomaterials: synthesis, properties, modifications, and applications," Chemical Reviews, vol. 107, no. 7, pp. 2891-2959, 2007.

[16] H. Cheng, B. Huang, and Y. Dai, "Engineering BiOX (X = $\mathrm{Cl}, \mathrm{Br}, \mathrm{I})$ nanostructures for highly efficient photocatalytic applications," Nanoscale, vol. 6, no. 4, pp. 2009-2026, 2014.

[17] X. Meng and Z. Zhang, "Facile synthesis of $\mathrm{BiOBr} / \mathrm{Bi}_{2} \mathrm{WO}_{6}$ heterojunction semiconductors with high visible-light-driven photocatalytic activity," Journal of Photochemistry and Photobiology A: Chemistry, vol. 310, pp. 33-44, 2015.

[18] X. Meng, L. Jiang, W. Wang, and Z. Zhang, "Enhanced photocatalytic activity of $\mathrm{BiOBr} / \mathrm{ZnO}$ heterojunction semiconductors prepared by facile hydrothermal method," International Journal of Photoenergy, vol. 2015, Article ID 747024, 9 pages, 2015.

[19] X. Meng and Z. Zhang, "Bismuth-based photocatalytic semiconductors: introduction, challenges and possible approaches," Journal of Molecular Catalysis A: Chemical, vol. 423, pp. 533549, 2016.
[20] J. Zhang, F. Shi, J. Lin et al., "Self-assembled 3-D architectures of $\mathrm{BiOBr}$ as a visible light-driven photocatalyst," Chemistry of Materials, vol. 20, no. 9, pp. 2937-2941, 2008.

[21] T. Xiong, F. Dong, and Z. Wu, "Enhanced extrinsic absorption promotes the visible light photocatalytic activity of wide bandgap $(\mathrm{BiO})_{2} \mathrm{CO}_{3}$ hierarchical structure," RSC Advances, vol. 4, no. 99, pp. 56307-56312, 2014.

[22] T. Xiong, H. Huang, Y. Sun, and F. Dong, "In situ synthesis of a C-doped $(\mathrm{BiO})_{2} \mathrm{CO}_{3}$ hierarchical self-assembly effectively promoting visible light photocatalysis," Journal of Materials Chemistry A, vol. 3, no. 11, pp. 6118-6127, 2015.

[23] M. Paradís-Bas, J. Tulla-Puche, and F. Albericio, "The road to the synthesis of "difficult peptides"," Chemical Society Reviews, vol. 45, no. 3, pp. 631-654, 2016.

[24] J. Chen, M. Guan, W. Cai, J. Guo, C. Xiao, and G. Zhang, "The dominant 001 facet-dependent enhanced visible-light photoactivity of ultrathin $\mathrm{BiOBr}$ nanosheets," Physical Chemistry Chemical Physics, vol. 16, no. 38, pp. 20909-20914, 2014.

[25] J. Xia, S. Yin, H. Li, H. Xu, L. Xu, and Y. Xu, "Improved visible light photocatalytic activity of sphere-like $\mathrm{BiOBr}$ hollow and porous structures synthesized via a reactable ionic liquid," Dalton Transactions, vol. 40, no. 19, pp. 5249-5258, 2011.

[26] Z. Jiang, F. Yang, G. Yang et al., "The hydrothermal synthesis of $\mathrm{BiOBr}$ flakes for visible-light-responsive photocatalytic degradation of methyl orange," Journal of Photochemistry and Photobiology A: Chemistry, vol. 212, no. 1, pp. 8-13, 2010.

[27] M. Shang, W. Wang, and L. Zhang, "Preparation of $\mathrm{BiOBr}$ lamellar structure with high photocatalytic activity by CTAB as Br source and template," Journal of Hazardous Materials, vol. 167, no. 1-3, pp. 803-809, 2009.

[28] C.-H. Chiou and R.-S. Juang, "Photocatalytic degradation of phenol in aqueous solutions by $\mathrm{Pr}$-doped $\mathrm{TiO}_{2}$ nanoparticles," Journal of Hazardous Materials, vol. 149, no. 1, pp. 1-7, 2007.

[29] C. Suwanchawalit and S. Wongnawa, "Influence of calcination on the microstructures and photocatalytic activity of potassium oxalate-doped $\mathrm{TiO}_{2}$ powders," Applied Catalysis A: General, vol. 338, no. 1-2, pp. 87-99, 2008.

[30] M. A. Behnajady, B. Alizade, and N. Modirshahla, "Synthesis of $\mathrm{Mg}$-doped $\mathrm{TiO}_{2}$ nanoparticles under different conditions and its photocatalytic activity," Photochemistry and Photobiology, vol. 87, no. 6, pp. 1308-1314, 2011.

[31] C. C. Wong and W. Chu, "The direct photolysis and photocatalytic degradation of alachlor at different $\mathrm{TiO}_{2}$ and UV sources," Chemosphere, vol. 50, no. 8, pp. 981-987, 2003.

[32] R. P. S. Suri, J. Liu, D. W. Hand, J. C. Crittenden, D. L. Perram, and M. E. Mullins, "Heterogeneous photocatalytic oxidation of hazardous organic contaminants in water," Water Environment Research, vol. 65, no. 5, pp. 665-673, 1993.

[33] H. Gupta and S. Tanaka, "Photocatalytic mineralisation of perchloroethylene using titanium dioxide," Water Science and Technology, vol. 31, no. 9, pp. 47-54, 1995.

[34] D. Jiang, H. Zhao, S. Zhang, R. John, and G. D. Will, "Photoelectrochemical measurement of phthalic acid adsorption on porous $\mathrm{TiO}_{2}$ film electrodes," Journal of Photochemistry and Photobiology A: Chemistry, vol. 156, no. 1-3, pp. 201-206, 2003.

[35] W. Ling-Li, M. Wan-Hong, W. Shu-Lian et al., "The contrastive research in the photocatalytic activity of $\mathrm{BiOBr}$ synthesized by different reactants," Journal of Nanomaterials, vol. 2012, Article ID 619761, 9 pages, 2012.

[36] L. Li, S. Liu, and T. Zhu, "Application of activated carbon derived from scrap tires for adsorption of Rhodamine B," Journal of Environmental Sciences, vol. 22, no. 8, pp. 1273-1280, 2010. 
[37] W. Chu, W. K. Choy, and T. Y. So, "The effect of solution pH and peroxide in the $\mathrm{TiO}_{2}$-induced photocatalysis of chlorinated aniline," Journal of Hazardous Materials, vol. 141, no. 1, pp. 8691, 2007.

[38] X. Chang, M. A. Gondal, A. A. Al-Saadi et al., "Photodegradation of Rhodamine B over unexcited semiconductor compounds of $\mathrm{BiOCl}$ and $\mathrm{BiOBr}$," Journal of Colloid and Interface Science, vol. 377, no. 1, pp. 291-298, 2012.

[39] L. Zhang, X.-F. Cao, X.-T. Chen, and Z.-L. Xue, "BiOBr hierarchical microspheres: microwave-assisted solvothermal synthesis, strong adsorption and excellent photocatalytic properties," Journal of Colloid and Interface Science, vol. 354, no. 2, pp. 630636, 2011.

[40] T. Wu, G. Liu, J. Zhao, H. Hidaka, and N. Serpone, "Photoassisted degradation of dye pollutants. V. Self-photosensitized oxidative transformation of Rhodamine B under visible light irradiation in aqueous $\mathrm{TiO}_{2}$ dispersions," Journal of Physical Chemistry B, vol. 102, no. 30, pp. 5845-5851, 1998.

[41] P. Xiao, L. Zhu, Y. Zhu, and Y. Qian, "Room-temperature synthesis of $\mathrm{BiOBr}$ sub-microflowers and their photocatalytic properties," Journal of Nanoscience and Nanotechnology, vol. 12, no. 3, pp. 2008-2013, 2012.

[42] J. Wang, Y. Yu, and L. Zhang, "Highly efficient photocatalytic removal of sodium pentachlorophenate with $\mathrm{Bi}_{3} \mathrm{O}_{4} \mathrm{Br}$ under visible light," Applied Catalysis B: Environmental, vol. 136-137, pp. 112-121, 2013.

[43] J. Cao, B. Xu, B. Luo, H. Lin, and S. Chen, "Novel BiOI/BiOBr heterojunction photocatalysts with enhanced visible light photocatalytic properties," Catalysis Communications, vol. 13, no. 1, pp. 63-68, 2011.

[44] S. Shenawi-Khalil, V. Uvarov, Y. Kritsman, E. Menes, I. Popov, and Y. Sasson, "A new family of $\mathrm{BiO}\left(\mathrm{Cl}_{x} \mathrm{Br}_{1-x}\right)$ visible light sensitive photocatalysts," Catalysis Communications, vol. 12, no. 12, pp. 1136-1141, 2011.

[45] W. Wei, Y. Dai, and B. Huang, "First-principles characterization of Bi-based photocatalysts: $\mathrm{Bi}_{12} \mathrm{TiO}_{20}, \mathrm{Bi}_{2} \mathrm{Ti}_{2} \mathrm{O}_{7}$, and $\mathrm{Bi}_{4} \mathrm{Ti}_{3} \mathrm{O}_{12}$," Journal of Physical Chemistry C, vol. 113, no. 14, pp. 5658-5663, 2009.

[46] M. A. Shannon, P. W. Bohn, M. Elimelech, J. G. Georgiadis, B. J. Marĩas, and A. M. Mayes, "Science and technology for water purification in the coming decades," Nature, vol. 452, no. 7185, pp. 301-310, 2008.

[47] T. Y. Leung, C. Y. Chan, C. Hu, J. C. Yu, and P. K. Wong, "Photocatalytic disinfection of marine bacteria using fluorescent light," Water Research, vol. 42, no. 19, pp. 4827-4837, 2008.

[48] J. C. Yu, W. Ho, J. Yu, H. Yip, P. K. Wong, and J. Zhao, "Efficient visible-light-induced photocatalytic disinfection on sulfur-doped nanocrystalline titania," Environmental Science \& Technology, vol. 39, no. 4, pp. 1175-1179, 2005.

[49] Y. Hou, X. Li, Q. Zhao, G. Chen, and C. L. Raston, "Role of hydroxyl radicals and mechanism of escherichia coli inactivation on $\mathrm{Ag} / \mathrm{AgBr} / \mathrm{TiO}_{2}$ nanotube array electrode under visible light irradiation," Environmental Science \& Technology, vol. 46, no. 7, pp. 4042-4050, 2012.

[50] C. Hu, J. Guo, J. Qu, and X. Hu, "Photocatalytic degradation of pathogenic bacteria with $\mathrm{AgI} / \mathrm{TiO}_{2}$ under visible light irradiation," Langmuir, vol. 23, no. 9, pp. 4982-4987, 2007.

[51] M. Vaara, "Agents that increase the permeability of the outer membrane," Microbiological Reviews, vol. 56, no. 3, pp. 395-411, 1992.

[52] L.-S. Zhang, K.-H. Wong, H.-Y. Yip et al., "Effective photocatalytic disinfection of $\mathrm{E}$. coli $\mathrm{K}-12$ using $\mathrm{AgBr}-\mathrm{Ag}-\mathrm{Bi}_{2} \mathrm{WO}_{6}$ nanojunction system irradiated by visible light: the role of diffusing hydroxyl radicals," Environmental Science \& Technology, vol. 44, no. 4, pp. 1392-1398, 2010.

[53] P.-C. Maness, S. Smolinski, D. M. Blake, Z. Huang, E. J. Wolfrum, and W. A. Jacoby, "Bactericidal activity of photocatalytic $\mathrm{TiO}_{2}$ reaction: toward an understanding of its killing mechanism," Applied and Environmental Microbiology, vol. 65, no. 9, pp. 4094-4098, 1999.

[54] D. Zhang, M. Wen, B. Jiang, G. Li, and J. C. Yu, "Ionothermal synthesis of hierarchical $\mathrm{BiOBr}$ microspheres for water treatment," Journal of Hazardous Materials, vol. 211-212, pp. 104-111, 2012.

[55] J. C. Yu, Jiaguo, Wingkei, Zitao, and Lizhi, "Effects of Fdoping on the photocatalytic activity and microstructures of nanocrystalline $\mathrm{TiO}_{2}$ powders," Chemistry of Materials, vol. 14, no. 9, pp. 3808-3816, 2002. 

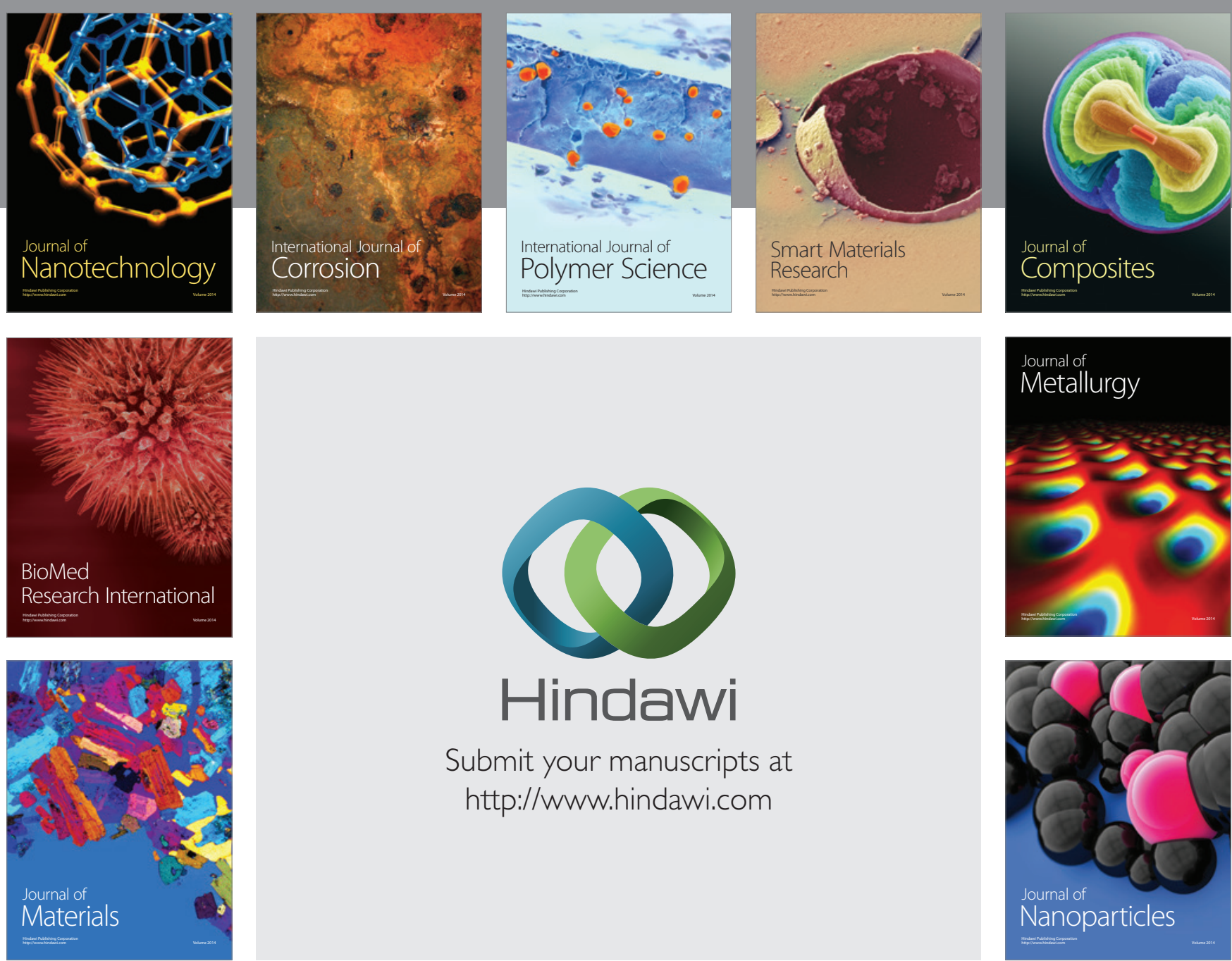

\section{Hindawi}

Submit your manuscripts at

http://www.hindawi.com

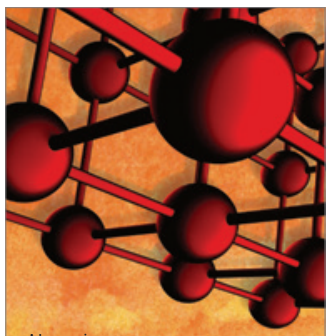

Materials Science and Engineering
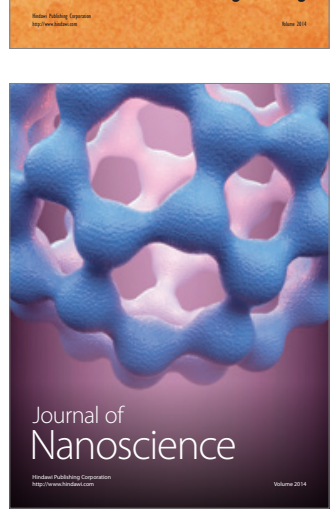
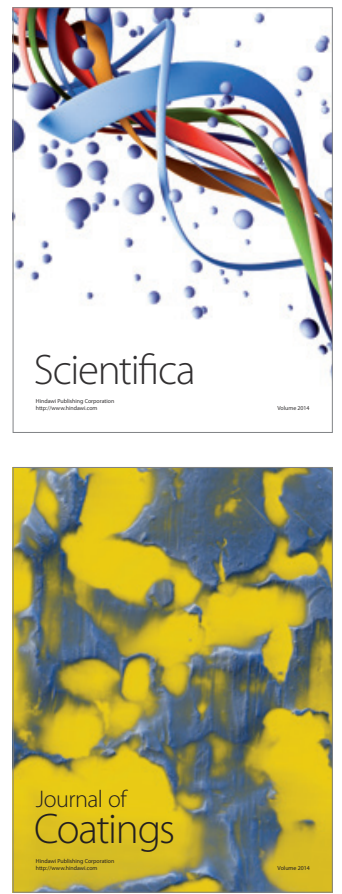
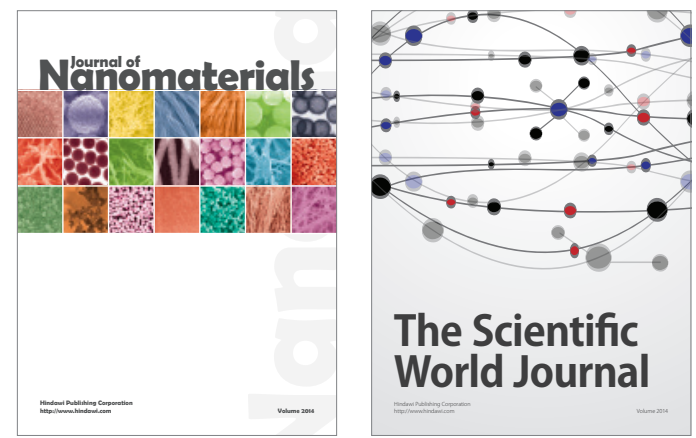

The Scientific World Journal
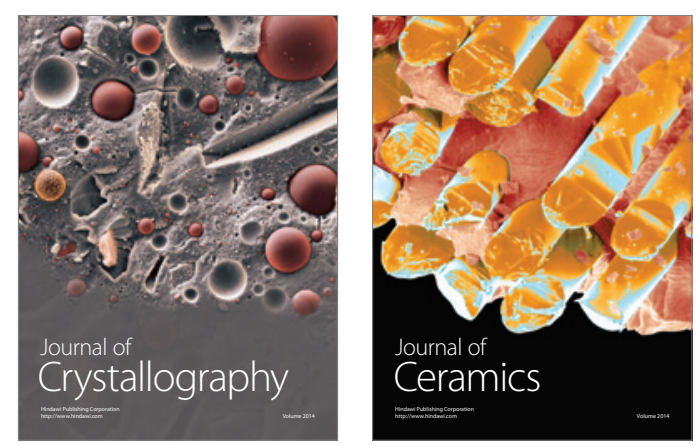
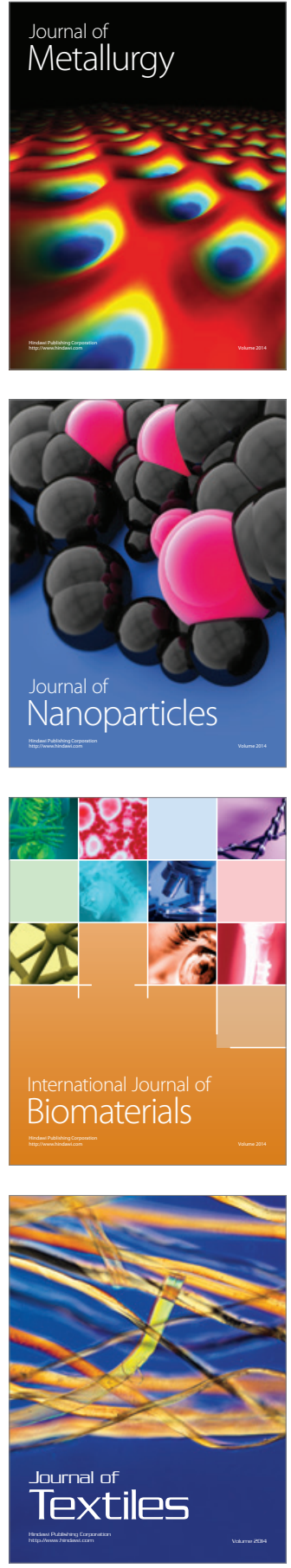